Vol. XXII, No.

\title{
Crow and Mallard Nesting in Close Proximity
}

by John B. Millar, Canadian Wildlife Service, Saskatoon

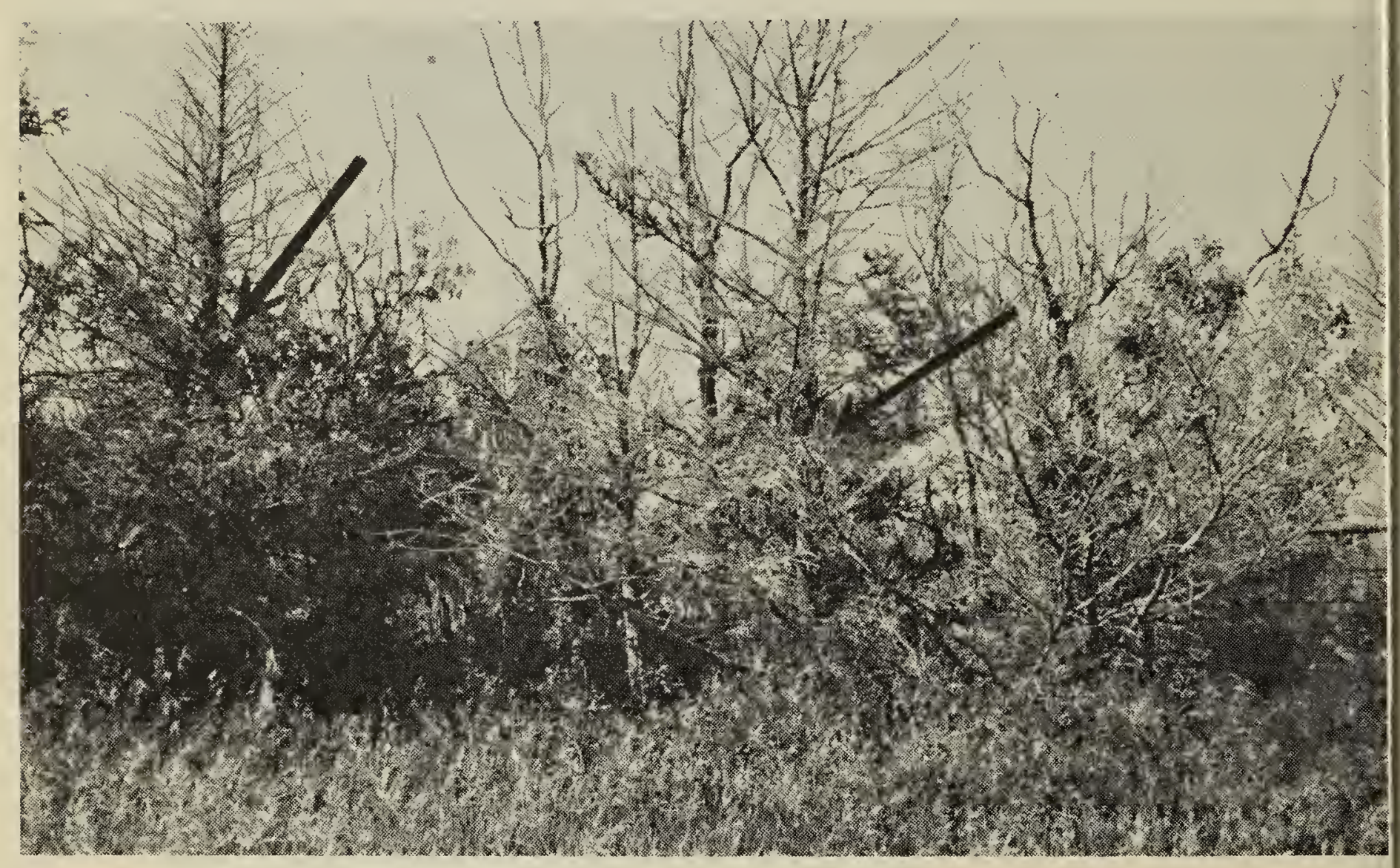

View of the shelterbelt on an abandoned farm east of Swift Current, Saskatchewan, showing the location of the nests of a crow (left-hand arrow) and a Mallard (righthand arrow).

On June 5, 1963, while passing an abandoned farmstead just east of Swift Current, Saskatchewan, I noticed a lone Common Crow (Corvus brachyrhynchos) perched on a branch of a dead tree in the shelter belt. Thinking that perhaps there would be a nest with young old enough to band, I stopped to investigate. A short search soon revealed a nest some seven or eight feet up in a small dead spruce. As I approached, a hen Mallard (Anas platyrhynchos) flushed from an old crow nest six feet up in another dead spruce not 15 feet from the first tree. I began to work my way through the underbrush to the Mallard's tree and as I did so eight newly hatched ducklings tumbled from the nest one by one and scurried away into the deep grass. A quick examination of the nest revealed that all eggs had hatched successfully. I then returned to the first nest and flushed a crow off a clutch of five eggs.

It is evident since the Mallard had hatched her brood while the crows were still incubating, that she had begun nesting before they arrived and therefore it seems certain that the crows would have discovered the duck while searching for a nest site. Furthermore, the positions of the two nests were such that the sitting birds were in full view of each other at all times. Considering the crow's reputation as a ruthless predator of duck nests it is noteworthy that this Mallard was able to incubate a clutch of eggs successfully in such an exposed position in close proximity to this breeding pair.

\section{AN UNUSUAL GULL ACCIDENT}

\author{
by John B. Millar,
}

Canadian Wildilife Service, Saskatoon

On September 19, 1961, I visited the site of a colony of Ring-billed Gulls (Larus delawarensis) and California Gulls (Larus californicus) on a peninsula (formerly an island) 
on the east shore of Last Mountain Lake, west of Cymric, Saskatchewan, to check for bands on the carcasses of birds that had died in the colony. As I picked up one dessicated carcass I noticed a wooden fishing plug bearing three treble hooks apparently entangled in the legs. Closer inspection revealed that a barb of one hook had pierced the web between the toes of the left foot, and a barb of a second was embedded in the skin over the tibia of the right leg, thus effectively hobbling the bird. In trying to reconstruct this incident it seems likely that the bird stepped on the hook which pierced the web of its foot and in the struggle to free itself threw the plug about in such a manner that the second hook embedded itself in the right ler. The actual cause of death might have been either starvation or predation as the entire front portion of the body, including the wings, was missing.

Positive species identification of the bird was not possible owing to the condition of the remains. However, on the basis of the size of the bird and the composition of the colony, which has been estimated by Stuart Houston (personal communication ) to be roughly 40 Ring-billed Gulls to one California Gull, it seems reasonable to suppose that it was a Ring-billed Gull.

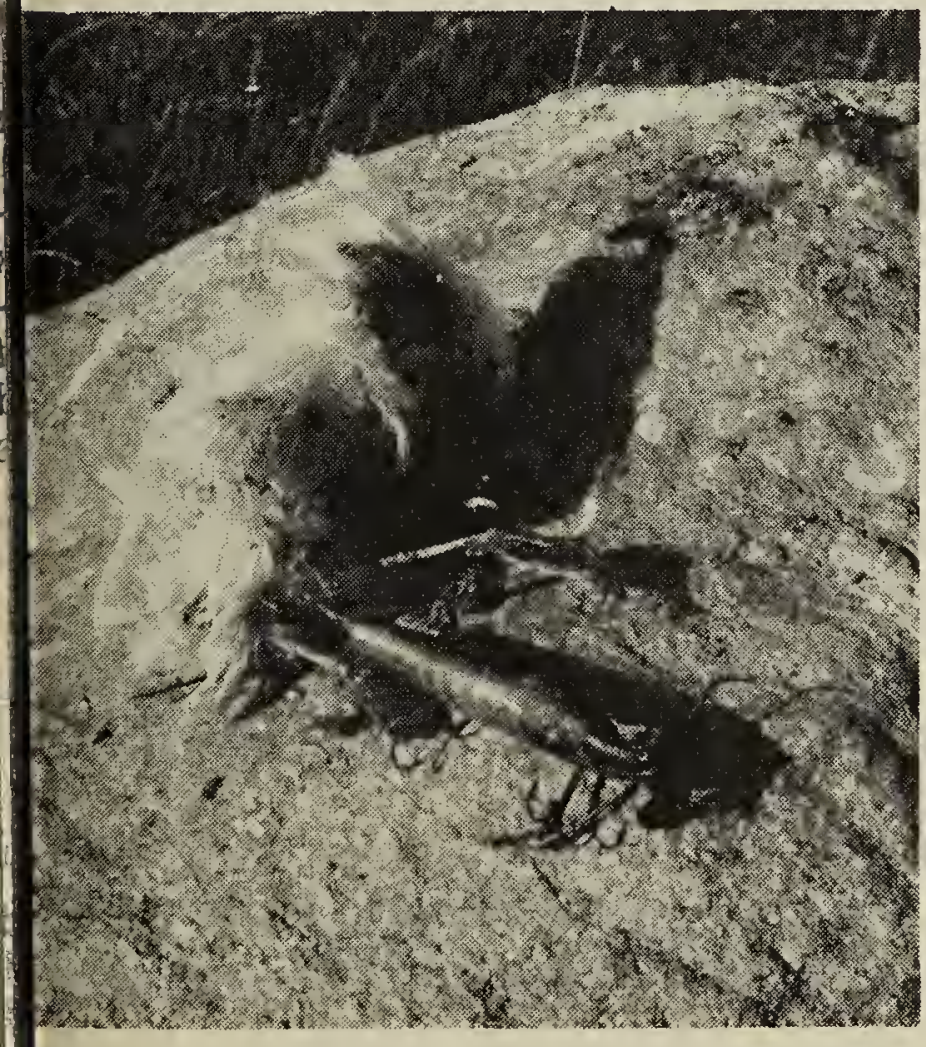

Carcass of gull showing the hooks of the fishing plug embedded in the legs.

\section{GRAY-CROWNED ROSY FINCH RECORD}

by Mrs. Hope Johnson, Ralston, Alberta

About the middle of February, 1964, I was down on the South Saskatchewan River banks, at a point scme 10 miles west of Medicine Hat. This is a badland area, with very deep eroded coulees. It was a fine but rather cool day. My 16-year-old son and a 10-year-old lccal boy were with me. We were quite surprised to see about five pairs of unusual (to me) birds flitting about in a deep sheltered gully. I had binoculars and was able to see quite a bit of detail of colour, beak shape, etc. I decided that they were "some sort of finch" but was quite unfamiliar with the species. After studying Peterson's A Field Guide to Western Birds I decided that they were Gray-crowned Rosy Finch. They were rather tame, and rather curious, as they flew close to us quite a few times, though quite rapidly. I do remember a small black patch abcve a light beak and a pink shading which was particularly well shown off as the birds flew by. The chestnu't coloured body reminded me of the colcur of a Ruddy Duck.

\section{DICKCISSEL AT OXBOW, SASK.}

\section{by Mrs. Keith Paton, Oxbow}

On June 13, 1964, I saw my first Dickcissel, sitting on a willow on a prairie trail. He was singing his best and looked exactly like "a little meadowlark".

Having been interested for many years in the birds here on our farm at Oxbow, we have been able to notice changes in bird populations, some of them apparently related to cycles of dry weather in Saskatchewan. The Lark Bunting has always been a very scarce bird here till this year. But this year we have seen a great many of them; and on a trip about 200 miles south into North Dakota, we saw hundreds of them! They were singing everywhere.

Editor's Note: The status of this species in Saskatchewar is discussed by Margaret Belcher in the Birds of Regina, 1961. Special Publ. No. 3, Sask. Nat. Hist. Soc., Regina. 